\title{
ФАКТОРЫ РИСКА СИНДРОМА ГИПЕРСТИМУЛЯЦИИ ЯИЧНИКОВ, СВЯЗАННЫЕ С ОВАРИАЛЬНОЙ СТИМУЛЯЦИЕЙ
}

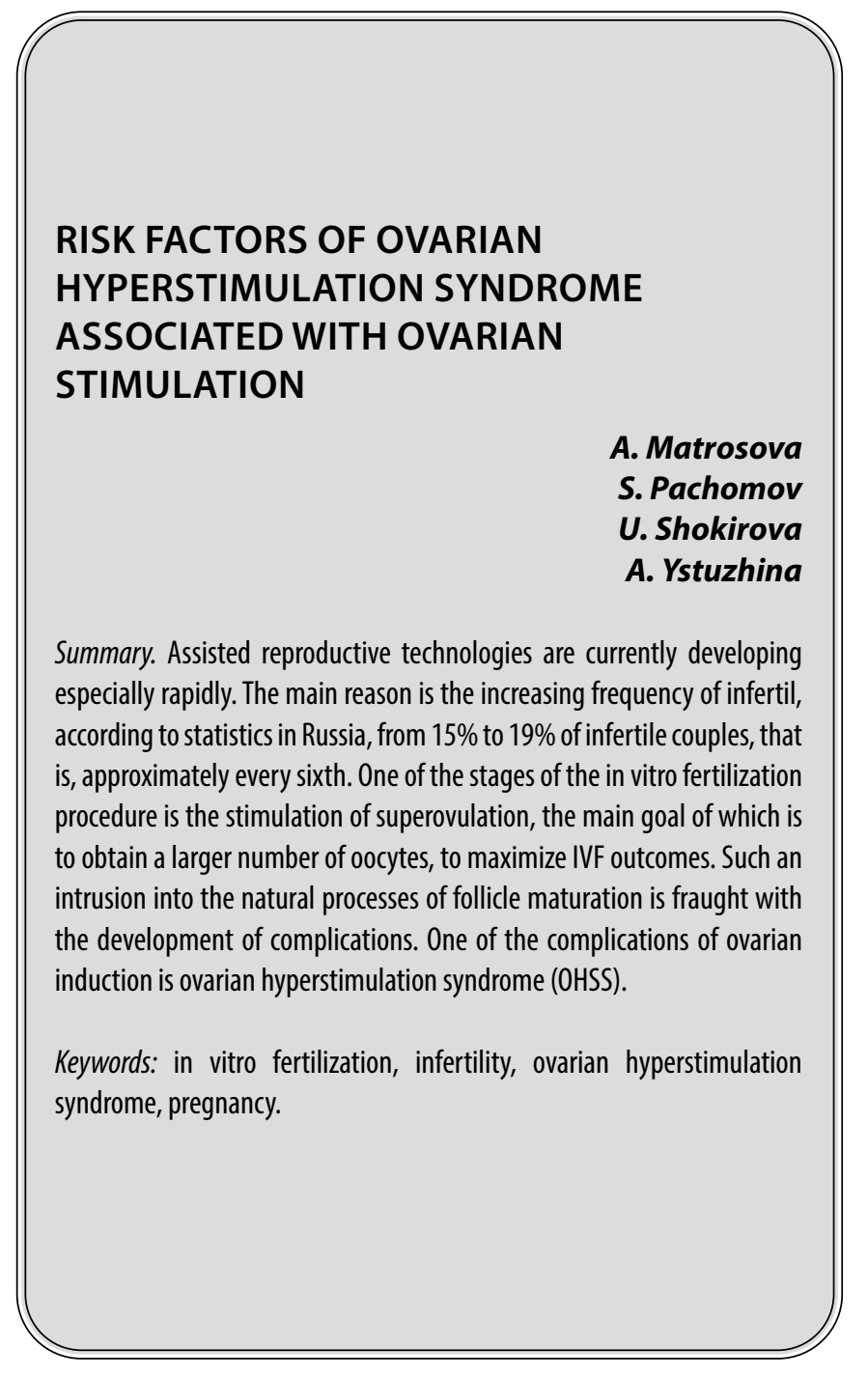

\section{Актуа^ьность}

C ГЯ - ятрогенное, жизнеугрожающее состояние, которое возникает ввиду неконтролируемого ответа яичников на введение гонадотропинов в процессе стимуляции овуляции. Клинические проявления синдрома являются следствием тех процессов, которые лежат в основе его патогенеза. Дискомфорт или даже боль в животе обусловлена увеличением яичников, а скопление жидкости в брюшной, плевральной полости и даже перикарде - увеличением сосудистой проницаемости и выходом жидкости в «третье» пространство (5). Выделяют легкую, среднюю и тяжелую форму синдрома. Легкая форма СГЯ характеризуется
Матросова Алина Владимировна

Соискатель, ФГАОУВО «Белгородский государственный национальный исследовательский университет»

alinamatrosova@inbox.ru

Пахомов Сергей Петрович

Д.м.н., профессор, ФГАОУ ВО «Белгородский государственный национальный исследовательский университет»

Шокирова Умеда Гайбуллоевна

Соискатель, ФГАОУВО «Белгородский государственный национальный исследовательский университет»

Устюжина Александра Сергеевна Соискатель, ФГАОУВО «Белгородский государственный национальный исследовательский университет»

Аннотация. Вспомогательные репродуктивные технологии в настоящее время развиваются особенно быстро. Причина этому - увеличивающаяся частота бесплодных браков, по статистике в России от 15\% до 19\% бесплодных пар, то есть примерно каждая шестая. Одним из этапов процедуры экстракорпорального оплодотворения является стимуляция суперовуляции, основная цель которой - получение большего количества ооцитов, что в разы повышает шансы на успех. Такое вторжение в естественные процессы созревания фолликулов чревато развитием осложнений. Одним из осложнений овариальной индукции является синдром гиперстимуляции яичников (СГЯ).

Ключевые слова: экстракорпоральное оплодотворение, бесплодие, синдром гиперстимуляции яичников, беременность.

двусторонним увеличением яичников с множественными фолликулярными кистами, вздутием живота и дискомфортом, легкой тошнотой и, реже, рвотой и диареей. При средней форме СГЯ к проявлениям, которые характерны для легкой стадии присоединяются ультразвуковые признаки асцита (2). Яичники часто увеличиваются до 12 см в диаметре. Тошнота и рвота возникают чаще и интенсивнее, чем при легкой степени. Появляется резкая прибавка веса (3). При тяжелой стадии к уже описанным симптомам присоединяется боль в животе, плевральный выпот, прибавка веса может достигать 15-20 кг. Часто присоединяются гоповолемия, олигурия или анурия. Наблюдаются изменения в общем и биохимическом анализе крови (4). Специфическим осложне- 
нием СГЯ являются тромбоэмболические осложнения и перекрут яичников.

Специфического лечения СГЯ не существует, как и нет четкого понимания патогенетических особенностей его развития. Поэтому клиницисты всего мира делают основной акцент на профилактике синдрома.

Доказано, что факторами риска развития СГЯ являются: возраст женщины (более молодой возраст связан с более мощным овариальным ответом), уровень АМГ (гормона > 3,6 нг/мл) (1), получение $>15$ фолликулов, диаметром >12 мм в результате овариальной индукции(4), Высокий и быстро растущий уровень эстрадиола крови >3500 пг/мл (5). К факторам риска так же относится наступление беременности, что связано с выработкой эндогенного ХГЧ, играет не маловажную роль в патогенезе данного осложнения.

Более детальное изучение факторов риска развития СГЯ может влиять на возможность его прогнозирования, ранней диагностики и своевременного лечения.

Целью нашей работы было изучить возможные факторы риска, которые связаны с параметрами стимуляции овуляции.

\section{Материалы и метолы}

За период 2008-2018г нами было проанализирован 671 протокол ЭКО. Исследование проводилось в отделении ВРТ на базе ОГБУЗ БОКБ Святителя Иоасафа. Все пациентки были разделены на 2 группы. Группа 1 ( $\mathrm{N}=56)$ включала женщин, у которых в ходе процедуры ЭКО возник СГЯ. Группа 2 ( $\mathrm{N=615)}$ состояла из женщин, которые не имели данного осложнения при проведении процедуры ЭКО.

\section{Результаты исслеАований}

В ходе исследования установлено, что СГЯ развивался достоверно реже при применении длинного протокола овариальной индукции $(35,71 \pm 6,4 \%$ случаев в группе женщин с СГЯ, против $72,36 \pm 1,8 \%$ случаев В группе контроля). В исследуемой группе пациенток с СГЯ стимуляцию овуляции начинали антагонистами гонадотропин-релизинг гормонов на 8,37 22,13 день цикла, а в контрольной группе гормоны назначались на 10,52 $\pm 5,72$ день менструального цикла, $(p<0,05)$.
При длинном протоколе ЭКО так же отмечалось достоверно более раннее начало стимуляции антагонистами гонадотропин-релизинг гормонов

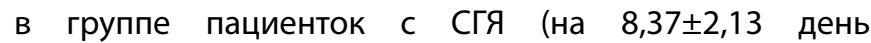
менструального цикла), в то время какв группепациенток без СГЯ начало протокола ЭКО было на 10,52 +5,72 день менструального цикла, $(p<0,05)$.

При оценке толщины эндометрия во время стимуляции овуляции на 4-7 день цикла толщина эндометрия достоверно отличалась в большую сторону в исследуемой группе $(5,7 \pm 2,04$ мм) по сравнению с контрольной группой пациенток, у которых данный

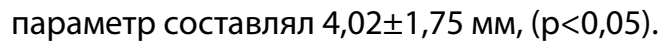

Помимо этого, наблюдалось увеличение толщины эндометрия соответственно дню менструального цикла в ходе стимуляции суперовуляции. Так, на 8-11 дни менструального цикла толщина эндометрия в группе пациенток с СГЯ составила 7,27士1,59 мм, в группе пациенток без данного осложнения этот показатель составлял 5,92 1,62 мм, а на 9-13 дни менструального

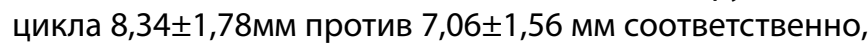
$(\mathrm{p}<0,05)$.

При оценке максимального диаметра фолликулов оказалось, что в исследуемой группе пациенток на 4-7 день менструального цикла отмечается

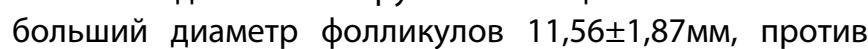
$10,74 \pm 2,79$ мм, $(p<0,05)$.

При изучении количества полученных ооцитов оказалось, что в исследуемой группе отмечался более высокий отклик на стимуляцию овуляции 22,34 $\pm 8,10$



\section{Зак^ючение}

Проблема СГЯ требует более глубокого изучения для четкого понимания патогенетических основ данного осложнения, выявления женщин из групп высокого риска и разработки индивидуального подхода к каждой пациентке.

Таким образом, применяемый протокол овариальной стимуляции, день начала стимуляции овуляции, толщина эндометрия и количество отобранных ооцитов могут рассматриваться как факторы риска развития СГЯ.

\section{ЛИТЕРАТУРА}

1. Serum anti-Müllerian hormone and antral follicle count as predictive markers of OHSS in ART cycles // URL: https://pubmed.ncbi.nlm.nih.gov/21882017/ (дата обращения: 12.12.2020).

2. Ovarian hyperstimulation syndrome // URL: https://www.ncbi.nlm.nih.gov/pmc/articles/PMC3205536/ (дата обращения: 11.12.2020). 
3. Pulmonary manifestations of severe ovarian hyperstimulation syndrome: a multicenter study // URL: https://pubmed.ncbi.nlm.nih.gov/10202873/ (дата обращения: 12.12.2020).

4. Ascites and liver test abnormalities during severe ovarian hyperstimulation syndrome // URL: https://pubmed.ncbi.nlm.nih.gov/10201472/ (дата 0бращения: 11.12.2020).

5. Синдром гиперстимуляции яичников (обзор литературы и клиническое наблюдение) // URL: http://radp.ru/db/20153/29-36.pdf (дата 0бращения: 12.12.2020).

(c) Матросова Алина Владимировна ( alinamatrosova@inbox.ru ), Пахомов Сергей Петрович,

Шокирова Умеда Гайбуллоевна, Устюжина Александра Сергеевна.

Журнал «Современная наука: актуальные проблемы теории и практики»

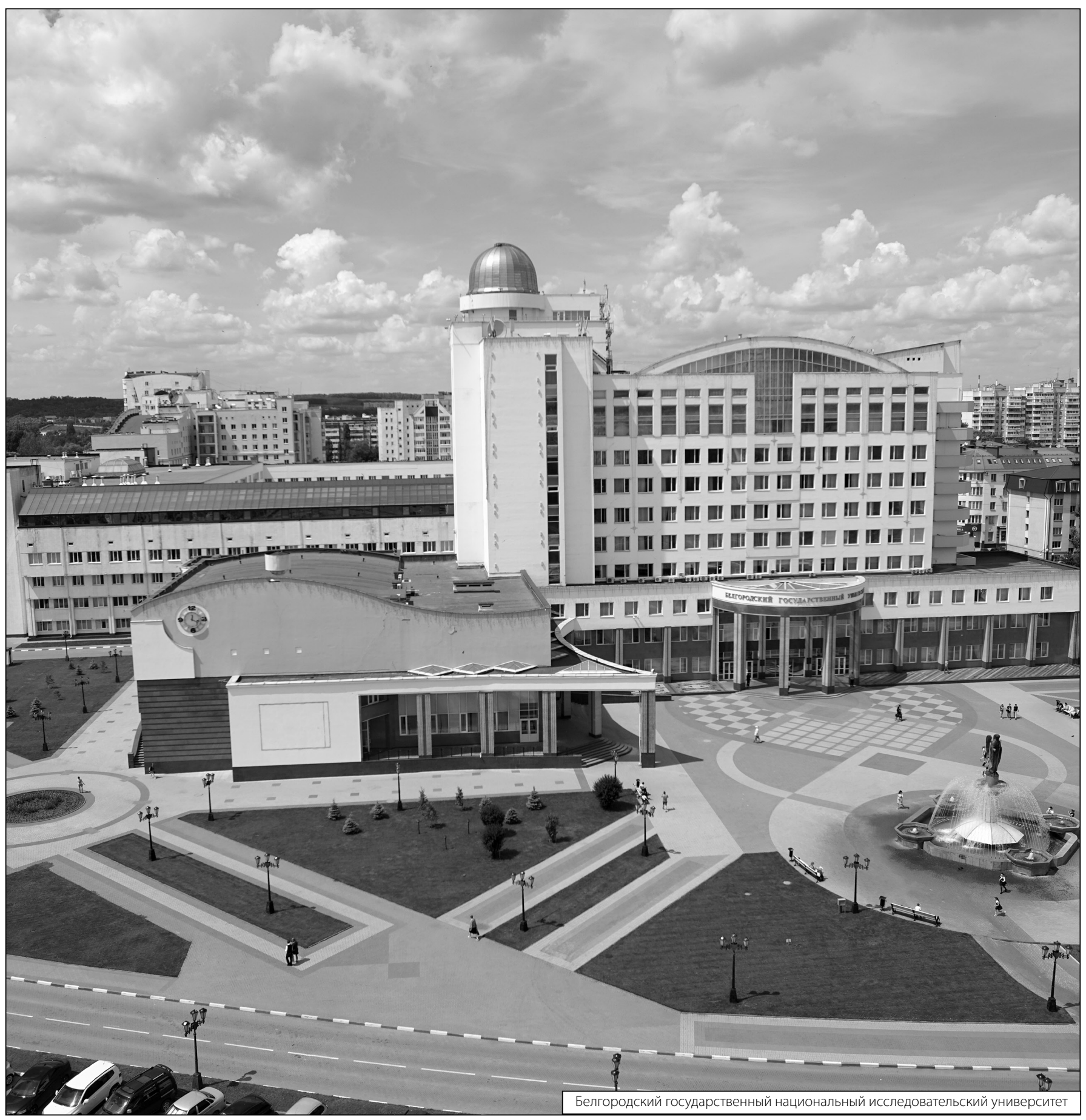

